\title{
Impact of heparanase on renal fibrosis
}

\author{
Valentina Masola ${ }^{1 \dagger}$, Gianluigi Zaza ${ }^{1 * \dagger}$, Maurizio Onisto ${ }^{2}$, Antonio Lupo ${ }^{1}$ and Giovanni Gambaro ${ }^{3}$
}

\begin{abstract}
Tubulo-interstitial fibrosis has been recognized as the hallmark of progression of chronic kidney disease, but, despite intensive research studies, there are currently no biomarkers or effective treatments for this condition. In this context, a promising candidate could be heparanase-1 (HPSE), an endoglycosidase that cleaves heparan sulfate chains and thus takes part in extracellular matrix remodeling. As largely described, it has a central role in the pathogenesis of cancer and inflammation, and it participates in the complex biological machinery involved in the onset of different renal proteinuric diseases (e.g., diabetic nephropathy, glomerulonephritis). Additionally, HPSE may significantly influence the progression of chronic kidney damage trough its major role in the biological pathway of renal fibrogenesis. Here, we briefly summarize data supporting the role of HPSE in renal damage, focusing on recent evidences that demonstrate the capability of this enzyme to modulate the signaling of pro-fibrotic factors such as FGF-2 and TGF- $\beta$ and consequently to control the epithelial-mesenchymal transition in renal tubular cells. We also emphasize the need of the research community to undertake studies and clinical trials to assess the potential clinical employment of this enzyme as diagnostic and prognostic tool and/or its role as therapeutic target for new pharmacological interventions.
\end{abstract}

\section{Background}

Although improvements in drug therapies over the years have significantly slowed the progression of chronic kidney disease (CKD) to end-stage renal disease (ESRD), we still remain far from being able to prevent a sizable proportion of patients from ultimately need for dialysis or transplantation [1]. Therefore, because of the large worldwide diffusion of this clinical condition, this represents an important issue in medicine.

The US Renal Data System's 2013 Annual Data Report indicates that more than $10 \%$ of the US adult population suffers from CKD [2]. In Italy, 13\% of people over age 40 have CKD [3]. CKD and ESRD have a significant impact on health care costs. In the US, the cost of CKD patients over age 65 exceeds $\$ 45$ billion [2].

Clinical-pathological studies have clearly shown that tubulo-interstitial fibrosis (TIF) is pivotally involved in the onset and progression of chronic renal damage and it could be considered a reliable prognostic marker of CKD, regardless of the etiology and the origin of the primary disease [4].

\footnotetext{
*Correspondence: gianluigi.zaza@univr.it

tValentina Masola and Gianluigi Zaza equally contributed to prepare and to write the present review

${ }^{1}$ Renal Unit, Department of Medicine, Verona University Hospital, Piazzale

A. Stefani 1, 37126 Verona, VR, Italy

Full list of author information is available at the end of the article
}

However, at the moment, main causes of renal fibrosis in developed countries are type 2 diabetes mellitus and ischemic/hypertensive nephropathy [5].

Additionally, despite numerous research efforts [6], no effective treatments or biomarkers are currently available for the progression of renal fibrosis. One interesting molecule that could be employed both as a biomarker and a pharmacological target is heparanase-1 (HPSE) an enzyme involved in the pathogenesis of several nephropathies [7] that cleaves heparan sulfate (HS) and thus takes part in the remodeling of the extracellular matrix (ECM) [8], a complex structure that acts as a scaffold for cell attachment, proliferation and differentiation, and modulates cell signaling [9].

The renal ECM consists of specific, specialized structures as the tubular and peritubular capillary basement membranes, and the glomerular basement membrane, but it also exists as an "amorphous" mesangial and interstitial matrix [10]. ECM remodeling by HPSE thus lies at the hub of networks integrating different mechanisms in renal fibrosis.

\section{Mechanisms of renal fibrosis}

During renal fibrosis, the accumulation of abnormal ECM alters the three-dimensional structure of all the renal structures (glomeruli, tubules, interstitium and 
vasculature) and it induces a failure of the physiological mechanisms of response to acute insult and/or tissue regeneration. Several factors could be involved in this deregulated machinery (e.g., cytokines, ROS, or inflammatory cells) [11].

The main macroscopic features of renal fibrosis (glomerulosclerosis, TIF, inflammatory infiltration, and loss of renal parenchyma, characterized by tubular atrophy, capillary loss, and podocyte depletion) are caused by several biological events including mesangial and fibroblast activation, monocyte/macrophage and T cell infiltration, and cell apoptosis. The accumulation of connective tissue and infiltration of inflammatory cells and myofibroblasts into the renal parenchyma result in irreversible organ damage [11]. Activated myofibroblasts in the tubular compartment and mesangial cells in the glomeruli are key producers of ECM (collagen IV, laminin, fibronectin) and major responsible for TIF and glomerulosclerosis, respectively. Both these cell lines have also properties similar to contractile smooth muscle, since they express $\alpha$-smooth muscle actin ( $\alpha$-SMA) [11]. In the kidney, myofibroblasts originate from several sources: (1) interstitial renal fibroblasts; (2) interstitial perivascular cells called pericytes; (3) fibrocytes; (4) tubular epithelial cells; and (5) endothelial cells $[6,12]$.

Tubular epithelial-mesenchymal transdifferentiation (EMT) into myofibroblasts, is a process first identified in mice and, more recently, in humans, representing an important source of these cells in kidney, contributes to the onset of TIF (Figure 1: top) and to the progression of CKD [13]. During this process, which ultimately determine renal fibrosis, the interstitial microenvironment is enriched with cytokines and chemokines released by the tubular epithelial cells in response to proteinuria, high glucose concentrations, advanced glycosylation end products (AGE), reactive oxygen species and hypoxia. Macrophages and lymphocytes attracted by the chemokines release additional factors, such as transforming growth factor- $\beta$ (TGF- $\beta$ ), epidermal growth factor (EGF), and fibroblast growth factor-2 (FGF-2) [14]. All these stimuli contribute to EMT of tubular epithelial cells.

In particular, TGF- $\beta$ seems to be primarily involved in the onset and progression of renal fibrosis in diabetic nephropathy (DN) [15]. In this pathological condition, the excess AGE and albumin filtering through the

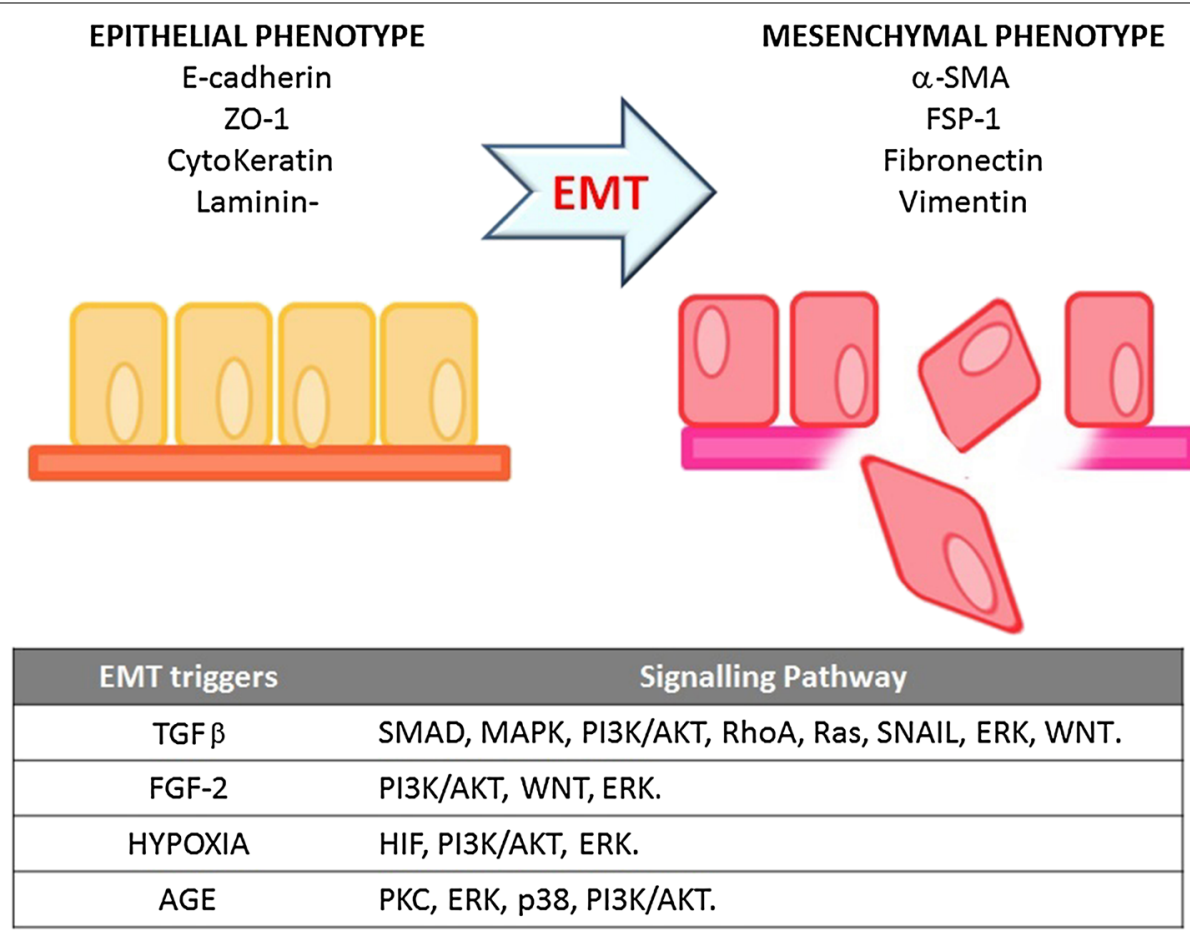

Figure 1 EMT process and signaling pathway. During EMT, tubular epithelial cells turn off the expression of adhesion molecules (E-cadherin, claudins and cytokeratins), and upregulate mesenchymal markers such as vimentin (VIM), fibronectin (FN), $\alpha$-SMA, and fibroblast-specific protein-1 (FSP1). Subsequently, they undergo a reorganization of the cytoskeleton and a change in their morphology. The transition process from epithelial to mesenchymal phenotype is gradual and it involves intermediate morphological changes [14]. Degradation of the tubular basement membrane and migration of the transformed epithelial cells into the interstitium complete the EMT. The table at the bottom summarizes the main EMT triggers and the signaling pathways that they activate. 
glomeruli also promotes EMT by directly stimulating the tubular cells to produce TGF- $\beta$ [16].

Many other factors have been identified as EMT triggers and, together with TGF- $\beta$, they activate multiple and, in some cases, "redundant" signaling pathways such as SMAD, MAPK, PI3-K/Akt, RhoA [17-19] (Figure 1: bottom).

\section{Heparanase}

HPSE is an endo- $\beta$ (1-4)-D-glucuronidase that cleaves the $\beta$ - $(1,4)$-glycoside bonds on the HS of HS-proteoglycans (HSPGs) leading to the production of HS fragments approximately $5-10 \mathrm{kDa}$ [19]. The active form of this enzyme is a heterodimer consisting of a $50 \mathrm{kDa}$ subunit associated non-covalently with an $8 \mathrm{kDa}$ subunit [20]. The HPSE gene $(50 \mathrm{~kb})$ is on chromosome $4 \mathrm{q} 21.3$ and comprises 14 exons and 13 introns coding a precursor (pre-HPSE) that is post-translationally converted first into pro-HPSE and then into mature HPSE [19]. The inactive pro-HPSE $(65 \mathrm{kDa})$ is transferred to the Golgi apparatus, where it is packaged in vesicles to be secreted from the cell. Once in the extracellular space, pro-HPSE interacts with syndecans and the pro-HPSE/syndecan complex is endocytosed [20]. Pro-HPSE can also be internalized by low-density lipoprotein receptor-related proteins and mannose 6-phosphate receptors [21]. Once inside the lysosomes, cathepsin-L cleaves the linker peptide from the pro-HPSE, yielding an heterodimer composed of 8- and 50-kDa subunits, thus activating HPSE (Figure 2).
Given its ability to degrade the HS chains, the main physiological function of heparanase is to regulate HS turnover and then participate in the remodeling of the ECM and basement membranes [20]. Nevertheless, HPSE triggers a number of signaling pathways by: (1) digesting HS chains and causing the release of growth factors and cytokines bound to HS, thereby regulating their free levels in the pericellular microenvironment; (2) interacting via its $\mathrm{C}$-terminal domain [22], with several transmembrane heparanase-binding proteins (HBP) and activating kinases such as Src, Akt, and p38 MAPK; (3) modulating the activity of the FGF- 2 and TGF- $\beta$ signaling cascades $[23,24]$ and (4) converting the soluble HS fragments of SDC1 from inhibitors into potent activators of FGF-2 signaling [25].

In non-pathological conditions, HPSE is produced by placental trophoblasts, blood-borne cells and keratinocytes [19]. Although the participation of HPSE in a number of physiological processes (e.g., embryo implantation and development, hair growth, and inflammatory processes) [26], researchers nowadays are mainly focusing on its involvement in pathological conditions including tumor progression and renal diseases.

\section{Heparanase and renal fibrosis}

Several studies of proteinuric renal diseases performed in animal models (puromycin amino nucleoside-induced nephrosis, streptozotocin-induced diabetic nephropathy and adriamycin nephropathy) and humans (diabetic nephropathy, membranous glomerulonephritis, IgA

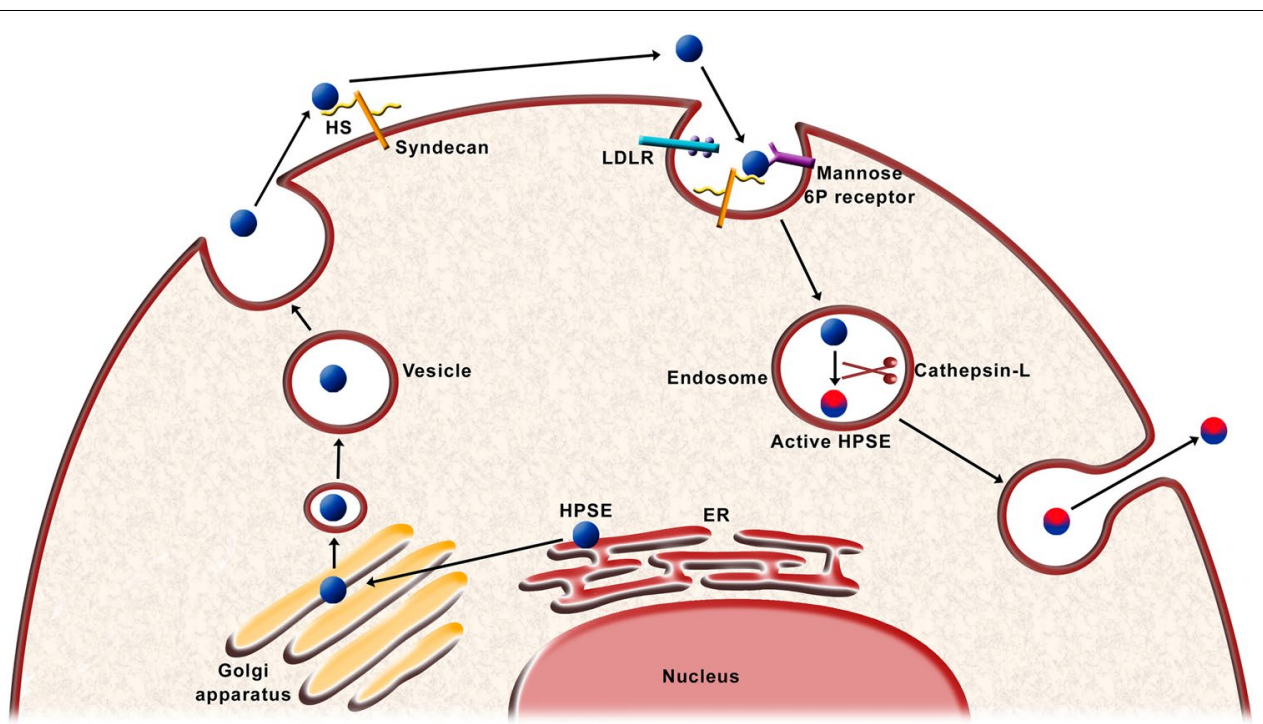

Figure 2 Graphical representation of HPSE maturation. The pro-enzyme is secreted from the Golgi complex. In the extracellular space, it interacts with syndecans or other receptors that mediate its endocytosis. The pro-enzyme is activated into lysosomes by cathepsin-L. Then active HPSE is secreted into the extracellular milieu. 
nephropathy, minimal change disease and dense deposit disease) have found a significant HPSE over-expression in the kidney tissue [27-29].

Additionally, since HPSE expression correlates inversely with HS content in the glomerular basement membrane, it has been suggested that the degradation of the glomerular HS by HPSE plays a role in the development of proteinuria $[28,30]$ particularly in diabetic nephropathy [7, 27, 29]. HPSE, constitutively expressed in human tubular epithelial cells, has also a physiological role in maintaining cellular and ECM homeostasis [31].

Changes in aforementioned balance, at least, partially determined by an abnormal HPSE regulation/activity, induce pathogenic mechanisms responsible for the onset of chronic kidney damage. In fact, in a model of type 1 diabetes induced by streptozotocin, HPSE-ko mice fail to develop chronic nephropathy [32] because protected against the onset of proteinuria and TIF [32].

HPSE expression is upregulated by transcription factors such as Sp1, GA-binding protein (GABP), ETS1, ETS2, early growth response-1 (EGR1), and downregulated by the transcription factor p53, and by DNA methylation. HPSE is also modulated by a variety of endogenous molecules: elastase, tissue plasminogen activator, thrombin, high glucose levels, angiotensin II and aldosterone, free radicals, pro-inflammatory cytokines, fatty acids, tissue necrosis factor- $\alpha$ (TNF- $\alpha$ ), vascular endothelial growth factor (VEGF), and estrogens [7, 19].

Moreover, several pro-fibrotic factors such as albuminuria, high glucose concentrations, advanced glycosylation end products (AGE), TGF- $\beta$ and FGF- 2 can upregulate HPSE expression [23, 31] (Figure 3A) by activating PI3K/AKT $[23,31]$, a signaling pathway involved

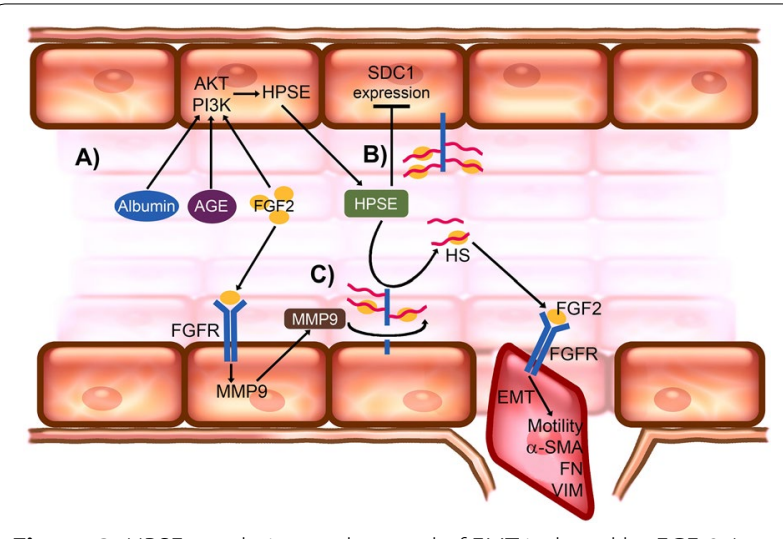

Figure 3 HPSE regulation and control of EMT induced by FGF-2. In the epithelial renal tubular cells (A), pro-fibrotic factors (albuminuria, AGE, and FGF-2) upregulate HPSE expression by activating PI3K AKT; B HPSE overexpression triggers HS degradation and modulates syndecan-1 (SDC1) expression; C soluble HS fragments of SDC1 are potent FGF-2 signaling activators and thus facilitate tubular cell EMT. in the EMT of renal tubular cells [33]. The overexpression of HPSE can trigger HS degradation and modulate the expression of syndecan-1 (SDC1), the most abundant HSPGs on epithelial cells (Figure 3B). In this condition, the abnormal remodeling of $\mathrm{HS}$ and SDC1 can increase the availability of growth factors (e.g., FGF- 2 and TGF- $\beta$ leading to TIF).

Our in vitro data indicated that renal tubular cells lacking HPSE did not undergo EMT induced by FGF-2 and TGF- $\beta$ [23]. This was mainly due to an over-expression of SDC1 on HPSE-silenced cells surface that has low affinity for FGF-2. In tubular cells lacking HPSE, the secondary impairment of PI3K/AKT pathway also jeopardizes the EMT induced by FGF-2. In addition, since FGF-2 is unable to increase the expression and activity of HPSE in such HPSE-deficient cells, the conversion of the soluble HS fragments of SDC1 from inhibitors into potent activators of FGF-2 signaling is prevented [23] (Figure 3C). Overall, HPSE is needed for FGF-2 to induce EMT in tubular cells, and to sustain FGF- 2 signaling.

HPSE regulates TGF- $\beta$-related EMT [34], as well as its production. In fact, diabetic HPSE-ko mice, contrarily to the wild-type, did not show TGF- $\beta$ increment in renal tissue and did not develop proteinuria, mesangial matrix expansion or TIF [32].

As demonstrated by our group, this effect could be partially explained by the fact that pro-fibrotic factors (albumin, AGE and FGF-2) need HPSE in order to upregulate TGF- $\beta$ expression in renal tubular cells. Additionally, a lack of HPSE delays the onset of EMT induced by TGF- $\beta$ and hampers the autocrine loop induced by TGF- $\beta$ [24].

Another way in which HPSE may contribute to the progression of renal damage lies in its effect to regulate inflammation [35]. This effect has been reported in other chronic diseases [36, 37].

In a recent paper, Gil et al. reported that HPSE-ko mice showed no significant infiltration of F4/80-positive macrophages in the renal parenchyma after the induction of type 1 diabetes, unlike wild-type animals [32]. Goldberg et al. [38] have also recently shown that HPSE fuels chronic inflammation in diabetic nephropathy: inactive HPSE produced by glomeruli and activated by cathepsin$\mathrm{L}$ released by tubular cells sustains a persistent activation of kidney-damaging macrophages, thus creating chronic inflammatory conditions and fostering macrophagemediated renal injury (Figure 4).

Overall, the ability of HPSE to regulate multiple mechanisms (glomerular permselectivity, tubular cell EMT, inflammation) makes it a central player in the fibrogenic process of diabetic nephropathy and, since similar mechanisms occur in other chronic kidney diseases (including chronic allograft dysfunction), it could be an effective therapeutic target. 


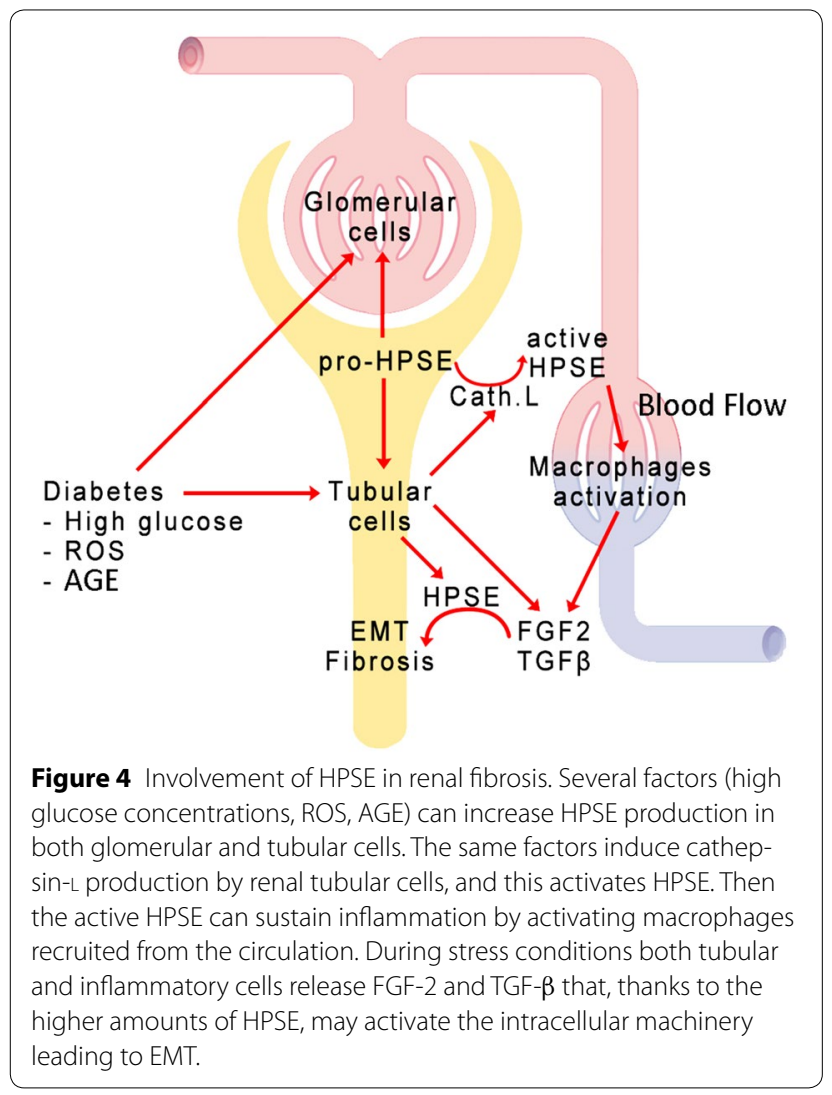

\section{Heparanase as a biomarker}

Heparanase has been detected in the plasma of neoplastic patients and its expression has been correlated with a better survival rate [39-41].

Increased urine and plasma levels of HPSE have been, also, reported in patients affected by a number of renal diseases (mainly diabetic nephropathy). In diabetes, HPSE levels correlated with blood glucose levels [42, 43] and, because involved in the atherosclerotic plaque development, it has been proposed as biomarker to early identify patients with DN at high risk to develop cardiovascular complications [44]. In kidney transplant recipients, plasma HPSE levels were associated with proteinuria and renal allograft function impairment [45].

Furthermore, our unpublished data, obtained by analyzing several chronic kidney diseases, suggest that HPSE levels are inversely associated with the degree of renal function impairment.

Cohen-Mazor et al. [46] reported that plasma levels of HPSE were higher in hemodialysis patients compared to healthy subjects probably due to degranulation of primed circulating PBMC during the dialysis session. This was later confirmed by our findings showing that HPSE expression in peripheral blood mononuclear cells $(\mathrm{PBMC})$ and plasma were significantly up-regulated in both peritoneal- and hemo-dialysis treated patients [47]. The significant correlation between HPSE plasma activity and C-reactive protein levels also demonstrated a close involvement of the microinflammation in the proteoglycan metabolism deregulation in uremic patients [47].

However, future investigations are necessary to elucidate whether urinary or plasma HPSE levels could serve as biomarkers of the onset and progression of fibrosis.

\section{Heparanase as pharmacological target}

In the last years, a number of HPSE inhibitors have been developed and some of them have entered clinical trials for cancer [48-50]. They include heparan sulfate mimetics, heparin-derived compounds, or other oligosaccharides that compete with the heparan sulfate chain for binding to heparanase [49]. Glycosaminoglycans such as sulodexide are effective HPSE inhibitors [51] and consequently have potential as drugs for the treatment of CKD and preventing progression to renal failure [52].

Important evidence of the utility of anti-HPSE therapies to control the progression of renal fibrosis comes from both in vitro and in vivo studies. In tubular cells, HPSE inhibition prevents the HS degradation induced by pro-fibrotic factors [31], EMT induced by FGF-2 [23, 51], and TGF- $\beta$ upregulation after treatment with pro-fibrotic factors [24]. In animal models, a beneficial effect on the onset and development of diabetic nephropathy, and on the renal overexpression of TGF- $\beta$ has been obtained with heparin-derived drugs [53], and sulodexide [54]. This issue was specifically investigated in mouse models of DN using the specific heparanase inhibitor SST0001, which markedly reduced the extent of albuminuria and renal damage [32].

Moreover, targeting HPSE in CKD could be useful for reducing the risk of cardiovascular complications [55]. Sulodexide seems to have some interesting favorable effects in the prevention and treatment of the complications of atherosclerosis, possibly supporting its role as HPSE inhibitor [56, 57].

\section{Conclusion}

Several studies revealed that HPSE plays a pivotal role in the pathogenesis of a great number of renal diseases (e.g., diabetic nephropathy, chronic allograft nephropathy) and in the progression of chronic renal damage.

However, at the moment, we are far from an employment of HPSE measurement in the "day by day" clinical practice and it is unquestionable that additional studies and clinical trials should be undertaken to assess its potential employment as diagnostic and prognostic tool and/or therapeutic target for new pharmacological interventions. 


\section{Abbreviations}

AGE: advanced glycosylation end products; CKD: chronic kidney disease; DN: diabetic nephropathy; ESRD: end-stage renal disease; EGF: epidermal growth factor; EMT: epithelial-mesenchymal transdifferentiation; ECM: extracellular matrix; FGF-2: fibroblast growth factor-2; HPSE: heparanase-1; HS: heparan sulfate; HSPGs: HS-proteoglycans; PBMC: peripheral blood mononuclear cell; SDC1: syndecan-1; TNF- $\alpha$ : tissue necrosis factor- $\alpha$; TLRs: toll-like receptors; TGF$\beta$ : transforming growth factor- $\beta$; TIF: tubulo-interstitial fibrosis; VEGF: vascular endothelial growth factor.

\section{Authors' contribution}

VM, GZ and GG conceived the work and wrote the manuscript, MO helped to draft the manuscript, AL participated in the design and coordination of the work. All authors read and approved the final manuscript.

\section{Author details}

${ }^{1}$ Renal Unit, Department of Medicine, Verona University Hospital, Piazzale A. Stefani 1, 37126 Verona, VR, Italy. ${ }^{2}$ Department of Biomedical Sciences, University of Padova, Padua, Italy. ${ }^{3}$ Division of Nephrology and Dialysis, ColumbusGemelli Hospital Catholic University School of Medicine, Rome, Italy.

\section{Acknowledgements}

We thank Dr. Andrea Donadon for technical support in the preparation of the artwork.

\section{Compliance with ethical guidelines}

\section{Competing interests}

The authors declare that they have no competing interests.

Received: 16 February 2015 Accepted: 14 May 2015

Published online: 04 June 2015

\section{References}

1. Friedman SL, Sheppard D, Duffield JS, Violette S (2013) Therapy for fibrotic diseases: nearing the starting line. Sci Transl Med 5:167sr1

2. US Renal Data System, USRDS (2013) Annual data report: atlas of chronic kidney disease and end-stage renal Disease in the United States, National Institutes of Health, National Institute of Diabetes and Digestive and Kidney Diseases, Bethesda

3. Gambaro G, Yabarek T, Graziani MS, Gemelli A, Abaterusso C, Frigo AC et al; INCIPE Study Group (2010) Prevalence of CKD in northeastern Italy: results of the INCIPE study and comparison with NHANES. Clin J Am Soc Nephrol 5:1946-1953

4. Hewitson TD (2009) Renal tubulointerstitial fibrosis: common but never simple. Am J Physiol Renal Physiol 296:F1239-F1244

5. Go AS, Chertow GM, Fan D, McCulloch CE, Hsu CY (2004) Chronic kidney disease and the risks of death, cardiovascular events, and hospitalization. N Engl J Med 351:1296-1305

6. Duffield JS (2014) Cellular and molecular mechanisms in kidney fibrosis. J Clin Invest 124:2299-2306

7. Szymczak M, Kuźniar J, Klinger M (2010) The role of heparanase in diseases of the glomeruli. Arch Immunol Ther Exp (Warsz) 58:45-56

8. Ilan N, Elkin M, Vlodavsky I (2006) Regulation, function and clinical significance of heparanase in cancer metastasis and angiogenesis. Int J Biochem Cell Biol 38:2018-2039

9. Bosman FT, Stamenkovic I (2003) Functional structure and composition of the extracellular matrix. J Pathol 200:423-428

10. Genovese F, Manresa AA, Leeming DJ, Karsdal MA, Boor P (2014) The extracellular matrix in the kidney: a source of novel non-invasive biomarkers of kidney fibrosis? Fibrogenesis Tissue Repair 7:4

11. Liu Y (2006) Renal fibrosis: new insights into the pathogenesis and therapeutics. Kidney Int 69:213-217

12. LeBleu VS, Taduri G, O'Connell J, Teng Y, Cooke VG, Woda C et al (2013) Origin and function of myofibroblasts in kidney fibrosis. Nat Med 19:1047-1053

13. Lan HY (2003) Tubular epithelial-myofibroblast transdifferentiation mechanisms in proximal tubule cells. Curr Opin Nephrol Hypertens 12:25-29
14. Kanasaki K, Taduri G, Koya D (2013) Diabetic nephropathy: the role of inflammation in fibroblast activation and kidney fibrosis. Front Endocrinol (Lausanne) 4:7

15. Willis BC, Liebler JM, Luby-Phelps K, Nicholson AG, Crandall ED, du Bois RM (2005) Induction of epithelial-mesenchymal transition in alveolar epithelial cells by transforming growth factor-beta1: potential role in idiopathic pulmonary fibrosis. Am J Pathol 166:1321-1332

16. Hills CE, Squires PE (2010) TGF-beta1-induced epithelial-to-mesenchymal transition and therapeutic intervention in diabetic nephropathy. Am J Nephrol 31:68-74

17. Lee JM, Dedhar S, Kalluri R, Thompson EW (2006) The epithelial-mesenchymal transition: new insights in signaling, development, and disease. J Cell Biol 172:973-981

18. Carew RM, Wang B, Kantharidis P (2012) The role of EMT in renal fibrosis. Cell Tissue Res 347:103-116

19. Vreys V, David G (2007) Mammalian heparanase: what is the message? J Cell Mol Med 11:427-452

20. Vlodavsky I, Ilan N, Naggi A, Casu B (2007) Heparanase: structure, biological functions, and inhibition by heparin-derived mimetics of heparan sulfate. Curr Pharm Des 13:2057-2073

21. Vreys V, Delande N, Zhang Z, Coomans C, Roebroek A, Dürr J et al (2005) Cellular uptake of mammalian heparanase precursor involves low-density lipoprotein receptor-related proteins, mannose 6-phosphate receptors, and heparan sulfate proteoglycans. J Biol Chem 280:33141-33148

22. Fux L, Ilan N, Sanderson RD, Vlodavsky I (2009) Heparanase: busy at the cell surface. Trends Biochem Sci 34:511-519

23. Masola V, Gambaro G, Tibaldi E, Brunati AM, Gastaldello A, D'Angelo A et al (2012) Heparanase and syndecan-1 interplay orchestrates fibroblast growth factor-2-induced epithelial-mesenchymal transition in renal tubular cells. J Biol Chem 287:1478-1488

24. Masola V, Zaza G, Secchi MF, Gambaro G, Lupo A, Onisto M (2014) Heparanase is a key player in renal fibrosis by regulating TGF- $\beta$ expression and activity. Biochim Biophys Acta 1843:2122-2128

25. Kato M, Wang H, Kainulainen V, Fitzgerald ML, Ledbetter S, Ornitz DM et al (1998) Physiological degradation converts the soluble syndecan-1 ectodomain from an inhibitor to a potent activator of FGF-2. Nat Med 4:691-697

26. Li JP, Vlodavsky I (2009) Heparin, heparan sulfate and heparanase in inflammatory reactions. Thromb Haemost 102:823-828

27. van den Hoven MJ, Rops AL, Vlodavsky I, Levidiotis V, Berden JH, van der Vlag J (2007) Heparanase in glomerular diseases. Kidney Int 72:543-548

28. Kramer A, van den Hoven M, Rops A, Wijnhoven T, van den Heuvel L, Lensen J et al (2006) Induction of glomerular heparanase expression in rats with adriamycin nephropathy is regulated by reactive oxygen species and the renin-angiotensin system. J Am Soc Nephrol 17:2513-2520

29. Garsen M, Rops AL, Rabelink TJ, Berden JH, van der Vlag J (2014) The role of heparanase and the endothelial glycocalyx in the development of proteinuria. Nephrol Dial Transpl 29:49-55

30. van den Hoven MJ, Rops AL, Bakker MA, Aten J, Rutjes N, Roestenberg $P$ et al (2006) Increased expression of heparanase in overt diabetic nephropathy. Kidney Int 70:2100-2118

31. Masola V, Gambaro G, Tibaldi E, Onisto M, Abaterusso C, Lupo A (2011) Regulation of heparanase by albumin and advanced glycation end products in proximal tubular cells. Biochim Biophys Acta 1813:1475-1482

32. Gil N, Goldberg R, Neuman T, Garsen M, Zcharia E, Rubinstein AM et al (2012) Heparanase is essential for the development of diabetic nephropathy in mice. Diabetes 61:208-216

33. Lan A, Du J (2014) Potential role of Akt signaling in chronic kidney disease. Nephrol Dial Transpl (Epub ahead of print)

34. Loeffler I, Wolf G (2014) Transforming growth factor- $\beta$ and the progression of renal disease. Nephrol Dial Transplant 29(Suppl 1):i37-i45

35. You H, Gao T, Cooper TK, Brian Reeves W, Awad AS (2013) Macrophages directly mediate diabetic renal injury. Am J Physiol Renal Physiol 305:F1719-F1727

36. Lerner I, Zcharia E, Neuman T, Hermano E, Rubinstein AM, Vlodavsky I et al (2014) Heparanase is preferentially expressed in human psoriatic lesions and induces development of psoriasiform skin inflammation in mice. Cell Mol Life Sci 71:2347-2357

37. Lerner I, Hermano E, Zcharia E, Rodkin D, Bulvik R, Doviner V et al (2011) Heparanase powers a chronic inflammatory circuit that promotes colitisassociated tumorigenesis in mice. J Clin Invest 121:1709-1721 
38. Goldberg L, Rubinstein AM, Gil N, Hermano E, Li JP, van der Vlag J et al (2014) Role of heparanase-driven cascade in pathogenesis of diabetic nephropathy. Diabetes 63:4302-4313

39. Masola V, Maran C, Tassone E, Zin A, Rosolen A, Onisto M (2009) Heparanase activity in alveolar and embryonal rhabdomyosarcoma: implications for tumor invasion. BMC Cancer 9:304

40. Shafat I, Barak AB, Postovsky S, Elhasid R, Ilan N, Vlodavsky I et al (2007) Heparanase levels are elevated in the plasma of pediatric cancer patients and correlate with response to anticancer treatment. Neoplasia 9:909-916

41. Ben Arush MW, Shafat I, Ben Barak A, Shalom RB, Vlodavsky I, Ilan N (2009) Plasma heparanase as a significant marker of treatment response in children with Hodgkin lymphoma: pilot study. Pediatr Hematol Oncol 26:157-164

42. Shafat I, Ilan N, Zoabi S, Vlodavsky I, Nakhoul F (2011) Heparanase levels are elevated in the urine and plasma of type 2 diabetes patients and associate with blood glucose levels. PLoS One 6:e17312

43. Rops AL, van den Hoven MJ, Veldman BA, Salemink S, Vervoort G, Elving LD et al (2012) Urinary heparanase activity in patients with Type 1 and Type 2 diabetes. Nephrol Dial Transpl 27:2853-2861

44. Masola V, Zaza G, Onisto M, Lupo A, Gambaro G (2014) Glycosaminoglycans, proteoglycans and sulodexide and the endothelium: biological roles and pharmacological effects. Int Angiol 33:243-254

45. Shafat I, Agbaria A, Boaz M, Schwartz D, Baruch R, Nakash R et al (2012) Elevated urine heparanase levels are associated with proteinuria and decreased renal allograft function. PLoS One 7:e44076

46. Cohen-Mazor M, Sela S, Mazor R, Ilan N, Vlodavsky I, Rops AL et al (2008) Are primed polymorphonuclear leukocytes contributors to the high heparanase levels in hemodialysis patients? Am J Physiol Heart Circ Physiol 294:H651-H658

47. Zaza G, Masola V, Granata S, Pontrelli P, Sallustio F, Gesualdo L et al (2014) Dialysis-related transcriptomic profiling: the pivotal role of heparanase. Exp Biol Med (Maywood) 239:52-64

48. Masola V, Secchi MF, Gambaro G, Onisto M (2014) Heparanase as a target in cancer therapy. Curr Cancer Drug Targets 14:286-293
49. Naggi A, Casu B, Perez M, Torri G, Cassinelli G, Penco S et al (2005) Modulation of the heparanase-inhibiting activity of heparin through selective desulfation, graded $\mathrm{N}$-acetylation, and glycol splitting. J Biol Chem 280:12103-12113

50. Liu CJ, Chang J, Lee PH, Lin DY, Wu CC, Jeng LB et al (2014) Adjuvant heparanase inhibitor PI-88 therapy for hepatocellular carcinoma recurrence. World J Gastroenterol 20:11384-11393

51. Masola V, Onisto M, Zaza G, Lupo A, Gambaro G (2012) A new mechanism of action of sulodexide in diabetic nephropathy: inhibits heparanase-1 and prevents FGF-2-induced renal epithelial-mesenchymal transition. J Transl Med 10:213

52. Masola V, Zaza G, Gambaro G (2014) Sulodexide and glycosaminoglycans in the progression of renal disease. Nephrol Dial Transpl 29(Supp 1):i74-i79

53. Ceol M, Gambaro G, Sauer U, Baggio B, Anglani F, Forino M et al (2000) Glycosaminoglycan therapy prevents TGF-beta1 overexpression and pathologic changes in renal tissue of long-term diabetic rats. J Am Soc Nephrol 11:2324-2336

54. Yung S, Chau MK, Zhang Q, Zhang CZ, Chan TM (2013) Sulodexide decreases albuminuria and regulates matrix protein accumulation in C57BL/6 mice with streptozotocin-induced type I diabetic nephropathy. PLoS One 8:e54501

55. Afsar B, Turkmen K, Covic A, Kanbay M (2014) An update on coronary artery disease and chronic kidney disease. Int J Nephrol 2014:767424

56. Coccheri S, Scondotto G, Agnelli G, Palazzini E, Zamboni V; Arterial Arm of the Suavis (Sulodexide Arterial Venous Italian Study) group (2002) Sulodexide in the treatment of intermittent claudication. Results of a randomized, double-blind, multicentre, placebo-controlled study. Eur Heart J 23:1057-1065

57. Condorelli M, Chiariello M, Dagianti A, Penco M, Dalla Volta S, Pengo V et al (1994) IPO-V2: a prospective, multicenter, randomized, comparative clinical investigation of the effects of sulodexide in preventing cardiovascular accidents in the first year after acute myocardial infarction. J Am Coll Cardiol 23:27-34

\section{Submit your next manuscript to BioMed Central and take full advantage of:}

- Convenient online submission

- Thorough peer review

- No space constraints or color figure charges

- Immediate publication on acceptance

- Inclusion in PubMed, CAS, Scopus and Google Scholar

- Research which is freely available for redistribution

Submit your manuscript at

www.biomedcentral.com/submit
C Biomed Central 